\title{
Los primeros años de la encomienda de indios del valle de Copiapó a través de la visita de Santillán al reino de Chile en 1558
}

The First Years of the Encomienda of the Indians of the Valley of Copiapó through Santillan's Visit to the Kingdom of Chile in ${ }_{155} 8$

DOI: https://doi.org/I0.22380/20274688.1260

Recibido: 13 de mayo del 2020

ENRIQUE ALBERTO CORTÉS LARRAVIDE*

Universidad Sorbonne-Nouvelle enlicode2@hotmail.com

\section{R E S U M E N}

Este artículo estudia la encomienda de indios del valle de Copiapó, en Chile, a mediados del siglo XVI, mediante una visita y tasa realizada en 1558 durante el gobierno de don García Hurtado de Mendoza por el oidor de la Audiencia de Lima don Hernando de Santillán. El análisis de dicho documento nos permitirá ver cómo la economía colonial local, orientada hacia la explotación de los yacimientos auríferos del reino de Chile, se desarrolló en desmedro de la encomienda de Copiapó.

Palabras clave: indios de Copiapó, tasa de Santillán, encomienda, visita, oro, mit'a

* Doctor en Antropología, Universidad Sorbonne-Nouvelle Paris 3, París, Francia, y doctor en Historia, opción Etnohistoria, Universidad de Chile, Santiago, Chile. En la actualidad lleva a cabo una investigación acerca de la circulación de minerales en los Andes desde tiempos prehispánicos hasta inicios del periodo republicano, PHC Tournesol, "Marqueurs minéralogiques et traceurs de mobilité dans les cultures préhispaniques andines”. Investigador asociado al Centro de Investigación y de Documentación de las Américas de la Universidad Sorbonne-Nouvelle, Creda UM R 7227, y al Centro de Investigación sobre la América Prehispánica de la Universidad Lettres SorbonneUniversité, CeRAP EA 355 I. 


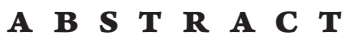

This article studies the encomienda of Indians from the Copiapó valley, in Chile, in the middle of the 16th century, through a visit and rate carried out in 1558 during the government of don García Hurtado de Mendoza by the oidor of the Audiencia of Lima don Hernando de Santillán. The results of the analysis of this document allow us to show not only the evolution of this encomienda through the weight generated by it, but also the profound changes generated by in the local colonial economy, which was based on the exploitation of the gold deposits of the kingdom of Chile.

Keywords: indians of Copiapó, rate of Santillán, encomienda, visita, gold, mit’a

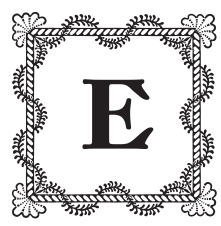

1 documento que aquí se analiza, la Relacion de las visitas y tasas que el señor licenciado Fernando de Santillan oydor de su Magestad hizo de la cibdad de Santiago provincias de Chile de los repartimientos de yndios de sus terminos y de la cibdad de la Serena, se halla en el Archivo General de Indias de Sevilla, fondo Justicia, dentro del juicio de residencia al oidor y presidente de la Real Audiencia de Quito Hernando de Santillán. Se publicó por primera vez de manera íntegra en el 2004, en una doble versión facsímil y paleográfica bajo la dirección del académico Hernán Cortés Olivares ${ }^{\mathrm{I}}$. Tal como este lo indica, hasta entonces solo se conocían las ordenanzas, que habían sido publicadas en cinco oportunidades, una por Medina (I9OI), otras cuatro por Jara (I961, 1965, I982 y 1987)², y habían constituido fuentes de estudio sobre la legislación y la organización temprana de la economía colonial, así como en torno al tema de los abusos de los encomenderos hacia la población aborigen chilena. Tras la publicación íntegra de Cortés Olivares esta no ha generado estudios detallados acerca del periodo temprano, exceptuando un interesantísimo trabajo sobre la situación de los niños a inicios de la Colonia (Zúñiga). El documento publicado en el 2004 está constituido, además de la ordenanza, de una visita ${ }^{3}$ y una tasa realizada en 1558 en las diferentes

I En la introducción, Cortés Olivares hace una síntesis muy completa sobre cómo se gestó el documento y los vericuetos que recorrió en el marco de la historiografía nacional (Introducción).

2 A partir de aquí se hace referencia exclusivamente a la publicación editada por Hernán Cortés Olivares et al. del 2004.

3 Durante el periodo colonial, las visitas constituyeron un elemento de control de la Corona por sobre las diferentes instituciones jerárquicamente inferiores, es decir, partiendo por las más importantes, como el Consejo de Indias, pasando por la visita a instituciones de ciudades americanas tales como 
encomiendas presentes en el reino de Chile, desde la más septentrional (valle de Copiapó) hasta aquellas situadas en regiones centrales. Quedaron sin visitar las encomiendas más meridionales de dicha capitanía general por haberse rebelado su población. A pesar de que la tasa fue redactada por el oidor Santillán, quien realizó la visita fue el encomendero Arias Pardo. El propósito de dichas ordenanzas, emprendidas por orden del nuevo gobernador del reino de Chile don Gabriel Hurtado de Mendoza, era regular el trabajo de los indios encomendados, para así salvaguardar la encomienda como institución, poniendo fin al constante abuso de los encomenderos sobre la población aborigen.

En este artículo tratamos en particular lo referente a la encomienda de Copiapó (véase figura I) ${ }^{4}$, que para ese entonces fue la que contabilizó un mayor número de encomendados en el reino. Conviene precisar que se trata del documento que recoge la mayor cantidad de información acerca de los habitantes del valle y ello durante todo el periodo colonial. No obstante, solo se menciona de manera explícita a los caciques hombres, contrariamente a otras visitas posteriores de las cuales se cuenta con mayores detalles respecto a nombres de integrantes de la encomienda, fueran estos caciques o no, mujeres u hombres, adultos, niños o reservados. A pesar de ello y las limitaciones inherentes a un documento como la visita, cuyo objetivo era recoger datos que supondrían consecuencias de diversa índole para las partes involucradas (indios visitados, encomendero,

la Audiencia, hasta llegar a las más subalternas, entre las que se hallaba la encomienda (Ruiz 3). En el caso de esta última, la visita tomaba la forma de interrogatorios cuantitativos (a veces cualitativos también) en cada encomienda visitada. El funcionario colonial recogía las declaraciones de los caciques acerca del número de indios en edad de trabajar, con el objetivo de implementar el tributo en la comunidad, a la vez que normaba el trabajo de cada uno de los miembros de la encomienda. En ciertas oportunidades, excepcionales eso sí, la encuesta iba más allá y recogía testimonios sobre las condiciones de vida y de trabajo y las relaciones con los españoles, en particular con el encomendero.

4 El valle de Copiapó se encuentra situado en el extremo sur del desierto de Atacama, entre las latitudes $27^{\circ} \mathrm{S}$ y $29^{\circ} \mathrm{S}$. Su clima árido contrasta con el carácter permanente de las aguas del río y de los afluentes que lo atraviesan (Jorquera, Manflas y Pulido). En su cabecera noreste se encuentra el inicio de la Puna atacameña; hacia el sur el fin del desierto y el inicio del Chile central; hacia el este, el noroeste argentino. El valle de Copiapó forma parte de la región conocida como el Norte Chico. Esta es una zona situada entre los valles de Copiapó y Choapa. Hay autores que la hacen llegar hasta el valle de Aconcagua. También es denominada la región de los Valles Transversales, el Norte Florido o el Norte Verde. Durante el periodo colonial dicha zona formaba parte de una unidad administrativa conocida como el corregimiento de La Serena. En tiempos prehispánicos, este territorio era parte del Kollasuyo; sus fronteras administrativas parecen haber sido similares a las del corregimiento de La Serena colonial, y respondía al nombre de provincia de Copayapo (E. Cortés, “¿Existió?”). 
administración colonial y Corona), la visita de 1558 brinda numerosos detalles en torno a la organización implementada por la administración durante los primeros ańos de la Colonia y permite explicar en parte la merma de la encomienda de indios del valle de Copiapó. Asimismo, contribuye a esclarecer los conocimientos acerca de dicha encomienda entre 155 I y $1558^{5}$.

\section{Los indios de Copiapó antes del contacto: más dudas que certezas}

Los datos disponibles para el periodo inicial de la presencia española en Chile, momento en el que la región era testigo de la caída del Tawantinsuyo, al que estaba anexada, no son precisos y además carecen de información acerca de las estructuras sociopolíticas locales en su conjunto. Tampoco poseemos registros concretos sobre las identidades étnicas de los pobladores del valle, ni sabemos si constituían o no una etnia.

A pesar de ello, varias investigaciones han mostrado avances al respecto. Así, los trabajos del historiador Jorge Hidalgo arrojaron cierta luz sobre las estructuras políticas en pie al momento del contacto. Dichos estudios demuestran que en ese periodo en los valles del Norte Chico, incluido el de Copiapó, existían señoríos duales, cada cacique gobernaba una mitad del valle — la parte alta y la parte baja- (Hidalgo). Hasta ahora, sin embargo, con las fuentes disponibles, se hace difícil determinar si dicha organización dual estaba presente en el valle de Copiapó antes de la anexión del territorio por el Tawantinsuyo, o bien si sería una estructura política implementada por los inkas que luego perduró tras su caída (E. Cortés, “¿Existió”).

Los análisis lingüísticos, basados en los escasos datos relacionados con la lengua que hablaban los pobladores del valle durante el siglo Xvi, han arrojado varias pistas. Es bastante probable que las lenguas presentes en los territorios circundantes al valle estuvieran ausentes en Copiapó, ya fueran aquellas habladas hacia el sur (mapuzungún), hacia el norte (likan-antai) o traídas por los inkas (quechua, aymara, pukina). No obstante, la presencia inkaica parece

$5 \quad$ Hace ya alrededor de medio siglo que el análisis de las visitas es un tema recurrente en la etnohistoria andina. John Murra fue el primer investigador en demostrar el interés de este tipo de documentos en la comprensión de las estructuras políticas, sociales y económicas, así como de la historia de los grupos visitados (Murra). 
haber influido en la lengua local puesto que la toponimia del valle, sin ser aymara, posee rasgos de esta última, perceptibles en la construcción de algunos fonemas (Itier). Además, podría estar relacionada con lenguas kakanas (E. Cortés, "La langue").

Por su parte, la arqueología muestra que el valle de Copiapó fue testigo de un desarrollo cultural homogéneo durante el periodo que antecedió a la llegada de los inkas (Castillo, "Los períodos"; Garrido; C. González). Sin embargo, si bien dichos datos tienden a mostrar que al momento de la llegada de los españoles a Chile los habitantes de Copiapó poseían cierta unicidad política, lingüística y territorial, se carece de datos fehacientes que permitan adentrarse más en la cuestión.

A nivel económico, los testimonios coloniales tempranos destacan el carácter polifacético de la producción local, datos corroborados por las investigaciones arqueológicas. La agricultura (maíz, papa, quinoa, frijol, ají, cucurbitáceas y algodón), conjugada con el pastoralismo de auquénidos, la caza de aves, la pesca marítima y la recolección de frutos locales y mariscos, era complementada con la minería y la producción alfarera, textil y armamentística. Los diferentes poblados estaban construidos en las cabeceras del río y a lo largo de este, cerca de terrazas fluviales. Hasta ahora poco se sabe de las relaciones que mantenían con poblaciones vecinas. Los inkas, acompañados de sus aliados diaguitas chilenos (poblaciones originarias del valle de Elqui) ocuparon el valle y lo anexaron al Tawantinsuyo $^{6}$.

\section{La instauración de la encomienda en el valle de Copiapó}

La conquista y la colonización hispana de América no pueden ser entendidas sin la implementación de la encomienda. Esta institución nació en las Antillas a finales del siglo xv cuando Colón estableció, primero, un tributo a la población autóctona en beneficio del rey, y luego servicios a favor de los colonos (Zavala I-2). En I5O3 dicho sistema fue legalizado por la reina Isabel la Católica (Zavala 4). Este acto pretendía crear un marco estructurador con el fin de que las diferentes

6 No se sabe con precisión en qué periodo entraron los inkas a Copiapó. Las estimaciones se extienden desde fines del siglo XIv hasta mediados del xv (Cornejo). 
colonias ultramarinas se rigieran por un mismo sistema sin importar la realidad local (M. Góngora). A ojos del economista estadounidense Yeager, ello se debió a razones puramente económicas puesto que institucionalizar la encomienda suponía mayores beneficios que legalizar la esclavitud (Yaeger). En I542 el servicio personal fue abolido. No obstante, más allá del marco legal que definía los contornos de esta forma jurídica, la encomienda tomó diferentes formas dependiendo de la realidad local, en particular de las necesidades y voluntades de los colonos, muchas veces plasmando estos últimos su concepción feudal de la sociedad (Romano). En Chile, dicha institución no cumplió solamente una función de regulación de la fuerza de trabajo disponible y de los tributos destinados a la Corona española, sino que permitió la puesta en marcha de un sistema sustentado en el servicio personal de hombres adultos, como se solía practicar en gran parte de los Andes, pero también de mujeres adultas, hombres adolescentes y a veces incluso niños, tal como se observa en la lectura de la primera visita efectuada al reino por Santillán, a pesar de las leyes que lo prohibían (Contreras). Además, las encomiendas que se otorgaron en Chile hasta entonces tuvieron como objetivo premiar a los conquistadores más importantes del reino por los servicios prestados a la Corona, pero por sobre todo incitarlos a finiquitar exitosamente la pacificación del territorio.

Lo ocurrido en Copiapó es un ejemplo de ello. En efecto, sus habitantes y aquellos de todo el Norte Chico se habían confederado, lo que dificultaba la colonización del reino. Por ese entonces el gobernador de Chile Pedro de Valdivia escribía:

También quiero advertir a vuestra Majestad de una cosa: que yo envié a poblar la cibdad de La Serena, por la causa dicha de tener el camino abierto, y hice Cabildo y les di todas las demás abtoridades que convenía en nombre de vuestra Majestad, y esto me convino hacer y decir; y porque las personas que allá envié fuesen de buena gana, les deposité indios que nunca nacieron, por no decirles habían de ir sin ellos a trabajos de nuevo, después de haber pasado los tan crecidos de por acá. (Valdivia, "Al emperador" 44-45)

La pacificación pretendía, por consiguiente, desplegar las fuerzas españolas en el sur del reino, financiándolas con la producción minera, especialmente oro, en toda la región septentrional chilena. En I544 el gobernador envió al capitán Juan Bohón a fundar la ciudad de La Serena y le encomendó previamente 
los habitantes del valle de Copiapó7, que aún estaban en pie de guerra. Bohón emprendería su pacificación en 1548 construyendo un fuerte en el centro del valle, con cuatro decenas de soldados. Un gran levantamiento regional acabaría primero con su vida y la de los suyos en Copiapó, en noviembre de aquel mismo año (Bibar I27*8; A. Góngora y Marmolejo 15), y en enero conllevaría la destrucción de la ciudad que había sido fundada pocos años antes. El valle solo sería realmente pacificado en I55I por el capitán Francisco de Aguirre, a quien le fueron encomendados los habitantes del valle dos años antes por Valdivia (Valdivia, "Merced" 22I-222).

El gobernador decidió igualmente legalizar por escrito la transmisión de dicha encomienda a Hernando, hijo de Francisco de Aguirre, en caso de que este último viniese a morir en su intento de pacificación regional (AGI, $G$, Chile, 50, n. ${ }^{\circ}$ 6). Con ello, Aguirre pasó a ser encomendero de todos los indios del valle de Copiapó, así como de ciertos caciques del valle de Elqui (los de Marquesa) que dependían hasta ese momento de Valdivia. Esto dio paso a la pacificación del valle y a la materialización de la encomienda (véase tabla I).

$\leftrightarrow$ TABLA I.

Sucesión de la encomienda de Copiapó, siglo XVI

\begin{tabular}{|c|l|l|}
\hline Periodo & \multicolumn{1}{|c|}{ Indios del valle de Copiapó } & $\begin{array}{c}\text { Indios de Marquesa } \\
\text { (valle de Elqui) }\end{array}$ \\
\hline I544-I548 & $\begin{array}{l}\text { Juan Bohón } \\
\text { (hasta su muerte, en noviembre de I548) }\end{array}$ & Pedro de Valdivia \\
\hline I549-1580 & Francisco de Aguirre \\
\hline I58I-1609 & Hernando de Aguirre, hijo de Francisco de Aguirre \\
\hline
\end{tabular}

Fuente: elaboración propia, con base en Valdivia, "Merced" 22I-222; AGI, G Chile, 50, n 6; ANCh, CG, vol. I55, $n^{\circ} 3$.

7 Por desgracia, esta cédula de encomienda no ha sido localizada aún; quizá haya desaparecido definitivamente. La primera referencia a ella se encuentra en un documento de 1549 (Valdivia, "Merced" 22I).

8 Dicha edición fue publicada en una doble versión facsímil y paleográfica, sus páginas numeradas con cifras arábigas, integrándose además tras dichos números un asterisco en cada página de la versión facsímil. 


\section{Los indios del valle de Copiapó en la visita del licenciado Santillán}

Los contactos entre españoles e indígenas que precedieron a estas cédulas de encomienda de 1544 y I548 fueron esporádicos y muchas veces violentos. De modo general, en los Andes las encomiendas se constituyeron sin que se tuviera conocimiento de las especificidades de cada territorio y de cada grupo presente en la región, a pesar de que en muchos casos hubo informantes locales que disponían de datos administrativos concretos (Pärssinen 260). Ignoramos qué llevó a Valdivia a otorgarle la encomienda de todos los pobladores del valle primero a Bohón y después a Aguirre, algo inusual en Chile puesto que en cada valle hubo más de un encomendero. ¿Se tenía constancia de que el conjunto de los habitantes de este territorio constituía un grupo sociopolítico homogéneo? Es un elemento que se puede barajar, a pesar de lo que afirmara Valdivia en 1545 que tiende a demostrar lo contrario (Valdivia, "Al emperador" 44-45). En efecto, en 1542 un grupo de soldados españoles enviados a Perú por Valdivia había sido emboscado y capturado, y dichos soldados fueron apresados por alrededor de tres meses en Copiapó. El capitán de esta expedición, Alonso de Monroy, pudo escapar, y no cabe duda de que una vez huido del valle debió haber transmitido a Valdivia alguna información al respecto\%. Además, es importante indicar que si bien en 1544 Valdivia no incluyó en la encomienda de Bohón los indios de Marquesa (en el valle de Elqui), sí lo hizo en I549. Esto indica que el gobernador de Chile habría tomado nota de que este último grupo tenía quizá una relación estrecha (política, económica, ¿étnica?) con aquellos de Copiapó.

9 Existen pocas evidencias que permitan afirmar que se hayan realizado informes acerca de los habitantes del Norte Chico durante los primeros años de contacto hispano-indígena, a excepción de aquellos escritos por el adelantado Diego de Almagro y por el clérigo Cristóbal de Molina. Almagro, tras sus primeras entradas a este territorio hacia 1536-1537, escribió uno al rey Carlos V contándole lo acaecido durante su expedición. Este documento nunca fue encontrado pero se presume que Oviedo y Herrera lo utilizaron, lo que hace de dichas crónicas verdaderas joyas para la historiografía del Norte Chico a pesar de que sus autores no hayan sido testigos de los hechos que describen. En lo referente a Molina, su relación no brinda detalles importantes acerca de los grupos autóctonos de la región. Se sabe que envió junto a este escrito una carta al rey español, además de mapas de las regiones que atravesó en compañía de Almagro. Estos documentos, sin embargo, se encuentran igualmente perdidos. 
No sabemos con certeza que así fuera en tiempos prehispánicos, aunque ciertos datos arqueológicos tienden a darle aval a esta eventualidad ${ }^{\mathrm{IO}}$.

Entre esta última cédula y la visita realizada en 1558 a Copiapó no se dispone de datos suplementarios. Se sabe que en dicha encomienda, hasta antes de la visita, la mit’a se aplicaba a un $35 \%$ más de la población. Además, hasta esas fechas, los indios encomendados no solo extraían oro en Andacollo (Torres 193), sino que estaban abocados a realizar labores agrícolas diversas también, como producir aguardiente de uva que se exportaba a Perú ya en 1556 (H. Cortés, "El origen"). La visita muestra que para la fecha habría i9o individuos en la encomienda, dependientes de cinco caciques, repartidos en trece pueblos, con un total de 49I tributarios, divididos de la siguiente forma (véase tabla 2):

- Un primer grupo, bajo la autoridad del cacique don Francisco, con 526 individuos, de los cuales 137 eran tributarios (un $26 \%$ del grupo), divididos en tres unidades. La primera estaría ocupando dos pueblos, el de Payatelme y el de Chañar. Ignoramos la localización del primer pueblo; el pueblo de Chañar debe corresponder al puesto administrativo inka situado hacia el norte de Copiapó, y que registraba el tributo que se enviaba a los inkas, aún vigente como tal en el periodo de los primeros contactos hispano-indígenas (Bibar $\left.19^{*}\right)$. Otras dos unidades fueron designadas como camanchacas pescadores, una ocupando una zona aún no identificada (¿Caldera?), y la otra más al norte, "en la costa hazia atacama" (¿Paposo?, ¿'Taltal?).

- Un segundo grupo tenía como cacique a don Diego, con 360 indios, de los cuales 92 eran tributarios (25\% del total). El grupo estaría a su vez dividido en dos unidades, una ocupando el pueblo de Paycandelme, del cual no se volverá a tener más referencias, y otra ubicada en el Puerto (Morro Moreno). Este última es igualmente designada como Camanchacas pescadores.

- Un tercer grupo, el menos numeroso, de 75 indios, era dirigido por el cacique Tiquitiqui. En este se registraban 19 tributarios $(25 \% \mathrm{del}$ total), mas no el nombre de la localidad en la que residían, con lo cual

Io La localidad de Marquesa es la única que ha arrojado cerámica Copiapó en todo el valle de Elqui (Cantarutti, comunicación personal sostenida el ro de enero del 201 I). 
se hace imposible identificarlo con precisión. Tiquitiqui aparece como la única autoridad étnica de la encomienda en ser monógama, lo que nos hace suponer, junto al bajo número de tributarios registrados en el grupo, que el poder económico del cacique debió de ser inferior al de sus pares.

- El cuarto grupo era dirigido por el cacique don Alonso y estaba dividido en dos unidades. La primera estaba integrada por 224 indios, de los cuales 70 serían tributarios ( $28 \%$ del total) y residían en el pueblo de Copiapó. La segunda estaba integrada por 314 individuos, de los cuales 65 declaraban ser tributarios (20\% del total).

- Por último, el quinto grupo estaba dirigido por los caciques Ticalñaca (llamado igualmente Tucma o Tical) y don Hernando. Estaba compuesto por tres unidades. La primera residía en Marquesa (IOS individuos). Las otras dos eran las de Paygane y Meldata que se componen de 27I indios. Del total (376 individuos), el $30 \%$ eran tributarios (alrededor de Ioo). Investigadores han sugerido que los pueblos de Meldata y de Paygane se encontraban en el valle de Elqui, cerca de Marquesa (Castillo, "Diaguitas" 87-88; H. Cortés, "Evolución” 34). Santillán no es claro al respecto. Sin embargo, no existen datos que apoyen estas hipótesis. Nosotros postulamos que dichos pueblos habría que situarlos en el valle de Copiapó. En efecto, en algunas fuentes de los siglos XVI y XVII se citan dos localidades del valle relacionadas con la actividad minera, Paynague y Zelbata (ANch, $C G$, vol. 578, s. n.), que curiosamente hacen pensar en Paygane y Meldata. 
$\rightarrow$ TABLA 2.

Caciques y unidades / pueblos según la visita de Santillán en I558

\begin{tabular}{|l|l|}
\hline \multicolumn{1}{|c|}{ Caciques } & \multicolumn{1}{c|}{ Unidades / pueblos } \\
\hline $\begin{array}{l}\text { Ticalcañaca (Tical, Tucma) } \\
\text { y don Hernando }\end{array}$ & $\begin{array}{l}\text { Paygane y Meldata } \\
\text { Marquesa }\end{array}$ \\
\hline Don Francisco & $\begin{array}{l}\text { Payatelme y Chañar } \\
\text { ¿? (camanchacas pescadores) } \\
\text { en la costa hacia Atacama (camanchacas pescadores) }\end{array}$ \\
\hline Tiquitiqui & ¿? \\
\hline Don Diego & $\begin{array}{l}\text { Paycandelme } \\
\text { El Puerto (camanchacas pescadores) }\end{array}$ \\
\hline Don Alonso & $\begin{array}{l}\text { Copiapó } \\
\text { ¿? }\end{array}$ \\
\hline
\end{tabular}

Fuente: elaboración propia con base en Santillán.

La encomienda fue tasada en 4000 pesos de oro anuales, 20 arrobas de pescado seco anuales ${ }^{11}$ y a 3 arrobas diarias de pescado fresco (I 3,5 toneladas anuales). Además, los caciques que aparecen citados en la visita, de los cuales no se vuelve a tener referencia precisa en documentos posteriores, debían contribuir a la construcción de la iglesia. Llama la atención que los indios de la encomienda de Copiapó fueran los únicos de todo el reino de Chile en haber sido tasados a tributar productos y oro, además de ser sometidos a la mit’a (que en Chile adoptaba la forma de servicio personal y de trabajo por turnos). Santillán justificó esta medida declarando que "los indios son mas capaces que ninguno de las dichas provincias” (Santillán I84), quizá al haber tomado nota de que en el valle el grupo encomendado se dedicaba a diferentes actividades económicas (agricultura, crianza de ganado, minería, metalurgia, explotación y tratamiento de productos marítimos), destacando por tanto la existencia de grupos especializados en diversos oficios importantes para el desarrollo de la economía colonial (véase tabla 3). No hay que olvidar que Santillán conocía con detalle la realidad peruana, en particular todo lo referente a la organización económica

I Veinte arrobas equivalen a $250 \mathrm{~kg}$, es decir, a $750 \mathrm{~kg}$ de pescado fresco antes de ser secado. 
y productiva prehispánica de los diferentes grupos étnicos de la región, lo que lo llevó quizá a asimilar el valle de Copiapó a zonas más septentrionales, en contraste con los grupos presentes en el reino de Chile (Jara 15 ).

$\rightarrow$ TABLA 3 .

Tributo y mit'a en Copiapó y en Marquesa según la visita de Santillán en 1558

\begin{tabular}{|c|c|c|c|}
\hline Caciques & Mit'a & Indios de servicio & $\begin{array}{c}\text { Tributo } \\
\text { anual }\end{array}$ \\
\hline $\begin{array}{l}\text { Ticalcañaca } \\
\text { (Tical, } \\
\text { Tucma) } \\
\text { don } \\
\text { Hernando }\end{array}$ & $\begin{array}{l}\text { Paygane y Meldata } \\
9 \text { yndios (deteneros) } \\
\text { I2 lavadores } \\
\text { Marquesa } \\
\text { I3 lavadores } \\
8 \text { deteneros }\end{array}$ & $\begin{array}{l}\text { Valle de Copiapó } \\
2 \text { yndios y } 2 \text { muchachos para carreteros } \\
6 \text { yndios que le ayuden a sembrar con } \\
\text { arados en sus tierras y en las minas } \\
8 \text { (yndios que le ayuden) a coger e } \\
\text { deservar } \\
2 \text { yndios para regar las chacras } \\
2 \text { yndios y } 2 \text { mochachos para porqueros } \\
\text { I yndio y i mochacho para que guarde } \\
\text { las cabras } \\
2 \text { yndios para hazer arados } \\
4 \text { yndios que le ayuden a beneficiar } \\
\text { la vina } \\
2 \text { yndios que acarreen yerba con } \\
\text { bestias } \\
2 \text { caballerizos } \\
\text { I yndio hortelano } \\
\text { I bateero } \\
2 \text { mochachos para su servicio } \\
2 \text { yndias para la cozina } \\
3 \text { panaderas } \\
\text { I yndia para barrer la casa } \\
\text { Marquesa } \\
\text { I yndio para guarda de yeguas } \\
\text { sementeras con arados en sus puebloso } \\
\text { en las minas } \\
4 \text { e } 4 \text { mochachos a coger e deservar } \\
2 \text { yndios para guardar las chacras }\end{array}$ & $\begin{array}{l}\text { De } \\
4000 \text { pesos } \\
\text { de oro } \\
20 \text { arrobas de } \\
\text { pescado seco } \\
3 \text { arrobas de } \\
\text { pescado fresco } \\
\text { diario }\end{array}$ \\
\hline
\end{tabular}




\begin{tabular}{|c|c|c|c|}
\hline Caciques & Mit'a & Indios de servicio & $\begin{array}{c}\text { Tributo } \\
\text { anual }\end{array}$ \\
\hline $\begin{array}{l}\text { Don } \\
\text { Francisco }\end{array}$ & $\begin{array}{l}\text { Payatelme, Chañar } \\
\text { y } 2 \text { pueblos en la } \\
\text { costa } \\
8 \text { yndios deteneros } \\
\text { I3 lavadores }\end{array}$ & & \\
\hline Tiquitiqui & $\begin{array}{l}\text { ¿? } \\
4 \text { yndios (deteneros) } \\
6 \text { lavadores }\end{array}$ & & \\
\hline Don Diego & $\begin{array}{l}\text { Paycandelme y } \\
\text { Puerto } \\
9 \text { yndios (deteneros) } \\
\text { I } 4 \text { lavadores }\end{array}$ & & \\
\hline Don Alonso & $\begin{array}{l}\text { Copiapó } \\
\text { Io deteneros } \\
\text { Is lavadores }\end{array}$ & & \\
\hline Total & $\begin{array}{l}\text { Ioo en el valle de } \\
\text { Copiapó } \\
\text { 2i en Marquesa }\end{array}$ & $\begin{array}{l}46 \text { en el valle de Copiapó } \\
\text { I6 en Marquesa }\end{array}$ & \\
\hline
\end{tabular}

Fuente: elaboración propia con base en Santillán.

\section{La tasa de 1558 y los nuevos desafíos de los indios encomendados}

Las medidas instauradas por Santillán en Copiapó tras la visita de Pardo tenían como objetivo cambiar radicalmente la relación del indio encomendado con el servicio que le prestaba a su encomendero, así como la relación de este último con la fuerza de trabajo encomendada. Se trató de la primera reglamentación implementada a este nivel en Chile. El licenciado Santillán, que había llegado al reino en 1557 con el nuevo gobernador don García Hurtado de Mendoza, emprendió dicha labor puesto que el servicio personal estaba generalizado y los indios vivían en un sistema cercano a la esclavitud (Santillán 194).

Las nuevas disposiciones no pretendían abolir el servicio personal, sino reglamentarlo para que su utilización no fuera en desmedro de los grupos 
encomendados. Sin embargo, a pesar de que Santillán disminuyó en un $35 \%$ el número de indios destinados a la mit'a en el valle (de 190 pasaron a ser I2I), paralelamente la encomienda contrajo la obligación de entregar al encomendero oro y alimentos, además de destinar 54 indios a tareas productivas agrícolas y ocho a tareas domésticas. ¿Qué consecuencias pudo haber tenido esta nueva organización en el devenir de los indios encomendados de Copiapó?

Los pescadores, que disponían de balsas que les permitían tener mayor movilidad en largas distancias en comparación con los indios del interior, fueron progresivamente desapareciendo de la zona. Mientras que en 1558 eran alrededor de 350, a inicios del siglo XviıI ya habían abandonado la costa aledaña. Así, en 1708 solamente se mencionaban dos tributarios, un adulto reservado con su esposa y dos niños (ANch, $C G$, vol. 48I, n. ${ }^{\circ} 46$ ), mientras que en I7I7 quedaba simplemente una cabaña (Frézier I55). Medio siglo antes de estos testimonios, en 1659, el encomendero del valle, Fernando Aguirre Riberos, bisnieto del conquistador Aguirre, se quejaba de que los pescadores de su encomienda habían huido hacia el norte: "indios camanchacas y chiangos, pescadores y no pescadores [...] que estuvieren en Cobija y costa de Atacama” (Bittmann 328).

En cuanto a los otros indios sujetos a la mit'a, muchos fueron destinados de forma directa o indirecta a la extracción de oro en Andacollo. En efecto, o bien trabajarían directamente en las faenas mineras, o bien en la producción de alimentos en las haciendas agrícolas. Dieciséis años más tarde, el español López de Velasco sostendría que "cuando los españoles entraron en él [valle de Copiapó], había muchos indios, ya se han acabado y no debe haber muchos más de ciento" (López de Velasco 264). La cifra se relaciona con la población tributaria del valle, sin incluir aquella de Marquesa, ni probablemente la de la costa. A pesar de ello, el contraste entre los datos de 1558 y los de 1574 no deja la menor duda en cuanto a la catástrofe demográfica en pie durante el siglo XVI, a causa del sistema impuesto por la producción de oro: de 689 tributarios para el valle, sin tomar en cuenta los de Marquesa, que en ese entonces no eran sino 5I, el grupo ya solo contabiliza poco más de un centenar de tributarios en todo el valle de Copiapó, y probablemente una cifra similar en Marquesa y Andacollo, si se hace referencia a la opinión de Lovera (79).

Datos posteriores referentes al siglo siguiente, todos provenientes de numeraciones realizadas en el marco de trámites para la reasignación de la encomienda a un nuevo encomendero, muestran una dinámica que continuó por similar rumbo. Así, en 1629 se contabilizaron solo 150 tributarios para toda la encomienda (ANCh, $C G$, vol. 48I, n. ${ }^{\circ}$ 46), cifra que aumentaría en siete en 1636 
(ANCh, CG, vol. 48I, n..$^{\circ}$ ), mientras que en 1654 los datos arrojan IIo tributarios (AGI, G, Chile, 322, n. ${ }^{\circ}$ IO8). Los últimos documentos que contabilizan la población encomendada del valle para el siglo datan de 1676 (ANCh, $R A$, vol. 50, s. n.), con 79 tributarios para la encomienda, y de 1677 , que muestra que en el valle únicamente quedaban veinte tributarios (ANCh, $R A$, vol. 50, s. n.).

Estas cifras arrojan, por un lado, un constante descenso del número de tributarios de la encomienda de Aguirre. Por otro lado, los datos provenientes del año I677 permiten inferir que la gran mayoría de los indios estaba siendo transferida de manera continua a Marquesa (y probablemente a Andacollo). No puede dejar de considerarse el que un número considerable de indios huyera. Por otro lado, se sabe por un expediente de 1685 que indios de Copiapó habían sido integrados a la encomienda de Paytanasa, en el valle vecino de Huasco. Algunos llevaban allí alrededor de tres décadas, otros medio siglo (ANCh, $R A$, vol. 2467, n. ${ }^{\circ}$ I4). Las faenas mineras y agrícolas diezmaban a la población encomendada del valle y liberaban tierras que acababan progresivamente en manos de españoles (E. Cortés, "La pérdida"), en particular en aquellas del linaje Aguirre, que poseía a su vez la encomienda de indios del valle de Copiapó.

\section{Reflexiones a partir de la visita del oidor Santillán: las vicisitudes de la encomienda de indios del valle de Copiapó}

La visita a los indios del valle de Copiapó que se llevó a cabo en 1558 arroja luces sobre varios procesos históricos que resultaron fatales para los grupos locales, dinámicas que por un lado se relacionaban con la conquista y la implementación de la colonia, así como aquellas que implicaban el porvenir de los indígenas del valle. A su vez, mediante la lectura del documento es posible vislumbrar parcialmente procesos relacionados con el tema inka en la zona, en especial aquel relacionado con la organización socioeconómica implementada durante la fase Tawantinsuyo.

No cabe la menor duda de que el sistema de encomienda, en su papel no solo como institución, sino también como herramienta de control de acceso a la mano de obra local, y por lo tanto a la producción de riqueza, fue clave en el impacto social, político, territorial y demográfico que tuvo en la población encomendada. La regulación implementada mediante la visita y la tasa de 1558 
debió de ser considerada por los indios del valle una probable mejora del estado en el que hasta ese momento se encontraban. ¿Qué puede decirse al respecto?

Ciertos datos, muy parciales, permiten afirmar que entre $155 \mathrm{I}$ y 1558 los indios encomendados en Aguirre ya estaban siendo utilizados en las faenas mineras de Andacollo. Hacia mediados de I55I, ya pacificada la región, se estaban explotando sus yacimientos de oro (Actas del Cabildo de Santiago 275). Menos de un año más tarde, en 1552 , se escucharon rumores de un levantamiento general de los indígenas de la zona, con lo que varios jefes étnicos que trabajaban en Andacollo fueron ejecutados, entre ellos uno de Copiapó, tal como lo declaró el español Alonso de Torres (193).

Es bastante probable que las condiciones que los indios experimentaban por ese entonces, tras su pacificación y la implementación del sistema productivo colonial, fueran contrarias a lo que esperaban y concebían como aceptable en pro de la paz. De hecho, la ejecución del gobernador del reino en 1554 provocó un intento de levantamiento en la zona, que no perduró (Torres 193). Se sabe que en Perú, a pesar de que el servicio personal había sido abolido por real cédula el 22 de febrero de 1549, los colonos seguían manteniéndolo sin el más mínimo tapujo (Bakewell 43-45). Por las declaraciones de Santillán, en Chile la situación sería aún peor para los indios (Santillán 194).

Ahora bien, las declaraciones de don Diego, cacique del pueblo de Paycandelme, estarían indicando que antes de la visita, la mit’a minera habría sido efectuada por los huérfanos, hayan sido estos mujeres u hombres (Santillán I78-I8I). Esto tiende a coincidir con el testimonio de Michimalongko, el gran señor del valle de Chile, quien una vez vencido propuso a los españoles que sus indios huérfanos o solteros ${ }^{12}$ trabajaran en las faenas mineras auríferas en Marga-Marga, siendo esto, según Lovera, una herencia de la mit’a implementada por los inkas (Lovera 54). Igualmente, conviene precisar que a pesar de que en ambos periodos (inka y colonial) la mit'a supuso para la comunidad una carga de trabajo suplementaria impuesta por una administración extranjera al valle, su funcionamiento fue diferente. Así, en tiempos inkaicos consistió en una carga de trabajo fija por rotación, sin un objetivo determinado de producción, mientras que en el periodo colonial supuso no solo contingentes más importantes de individuos destinados a ella, sino que los objetivos productivos

I2 Los solteros y los huérfanos constituyen una categoría de individuos muy vulnerable, puesto que por un lado no están en condiciones de constituir una descendencia (los solteros), o bien no tienen ascendencia que los mantenga (los huérfanos). 
conllevaron enormes esfuerzos por parte de la comunidad. La declaración del cacique don Diego muestra que los grupos del valle enviaban sesenta mineros (alipacamayos), en su gran mayoría hombres solteros, I30 lavadores, mayoritariamente huérfanas y huérfanos, así como un número indeterminado de indios de servicio. Además, puesto que la producción aurífera en Andacollo dependía de las lluvias, en una región con bajos índices de precipitaciones, limitadas al periodo del año que coincidía con las faenas agrícolas de preparación de la tierra, no cabe duda de que la encomienda del valle debió de haber sufrido el impacto del nuevo sistema de mit'a. Por otro lado, el sitio de Marquesa aparece en este panorama como esencial en esta organización colonial. Sabemos que entre los siglos XVII y xx fue una hacienda productora de ganado y productos agrícolas. La visita de 1558 no registra ningún mitayo destinado a Andacollo, no obstante encontrarse en el marco de la encomienda de Copiapó, el lugar más cercano a las minas. Pensamos que ello se debió a que ya hacia esa época Marquesa desempeñaba el papel de productora de alimentos para los mineros copiapinos de Andacollo. En efecto, en Marquesa no se registró ningún niño, pero sí $5 \mathrm{I}$ hombres adultos, 33 mujeres adultas, uno reservado, nueve reservadas y once jóvenes, lo que lleva a suponer que se trataría de un grupo que realizaba labores productivas. Esta suposición tiende a consolidarse cuando vemos que aparecen dependiendo de los caciques don Hernando y Tical, de los pueblos de Paygane y de Meldata, situados probablemente en el valle de Copiapó, en los cuales no se registra ningún soltero pero sí parejas de indios casados e hijos de estos últimos. Esta situación viene entonces a corroborar las declaraciones de don Diego, cacique de Paycandelme, y de Michimalongko, gran señor del valle de Chile, según los cuales solteros y huérfanos estarían asumiendo las obligaciones productivas por parte de las comunidades encomendadas.

\section{Conclusiones}

Las disposiciones de Santillán se entienden mejor cuando se toma en cuenta el contexto en el que fueron pensadas e implementadas. En efecto, la voluntad del gobernador Hurtado de Mendoza reflejaba en ese entonces la visión homogeneizadora con la que se pretendía construir la América colonial, ordenando desde lo más alto de la cúspide política, entiéndase la Corona española, todas las posesiones ultramarinas (M. Góngora). Es probable que a pesar de la carga impuesta por el tributo y el servicio personal, implementados en el 


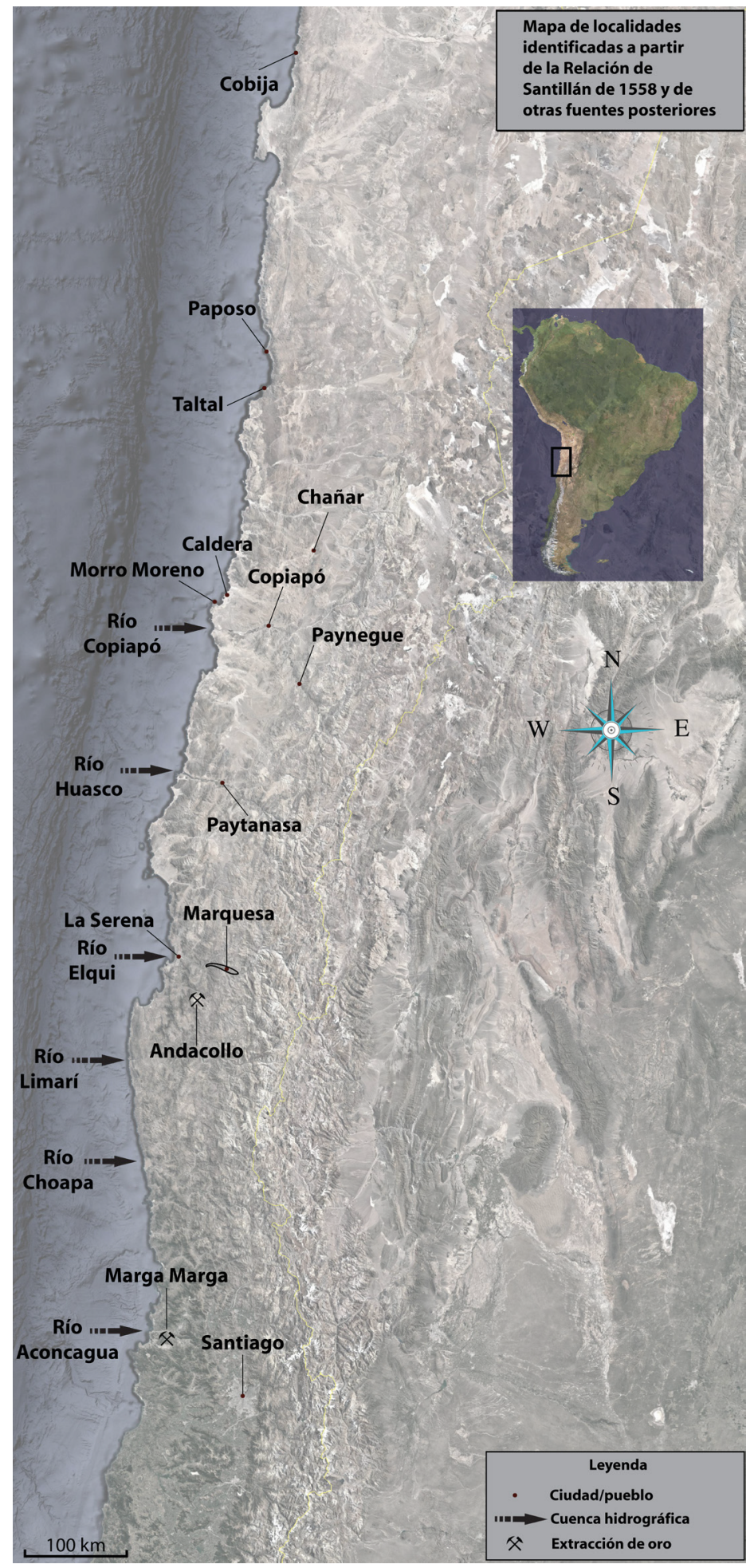

$\leadsto$ FIGURA I.

Mapa de

localidades identificadas a partir de la Relación de Santillán de 1558 y de otras fuentes posteriores

Fuente: elaboración propia con base en Santillán; Bibar; AGI, G, Chile, 50, $\mathrm{n}^{\circ}$ 6; ANCh, $C G$, vol. 578 , s. n. ${ }^{\circ}$; ANch, RA, vol. 2467, $n^{\circ}$ I4; Lovera. 
valle de Copiapó tras la visita y tasa consiguiente de Santillán, los indígenas del valle pudieran gozar de un descanso relativo y experimentar una mejora de sus condiciones de vida. Sin embargo, a casi cinco siglos de distancia de dicho proceso, no cabe duda de que la visita y consiguiente tasa, por más ambiciosas y justas que hayan sido para ese entonces, como lo pretendía probablemente Santillán, muestran que su objetivo se limitó a implementar una producción perenne en beneficio de la Corona y de la administración colonial más que un corpus legislativo que permitiera el auge de los grupos encomendados. En este sentido, tal como lo afirmara Ruggiero Romano hace ya cinco décadas, la implementación de la administración colonial, ya fuese impulsada desde España, simbolizada aquí por García Hurtado de Mendoza y Hernando de Santillán, o desde las Américas de la mano de los conquistadores, no fue ni más ni menos que una manera de reproducir sistemas sociopolíticos y económicos provenientes de Europa, en particular los feudales. En este sentido, Santillán reorganizó la encomienda local limitándose a concebir estructuras hispanas de tributo y servicio personal feudal, sirviéndose para Copiapó de lo implementado por los inkas previamente en él. Y esto último probablemente posibilitó la adhesión de los grupos locales, así como la de su encomendero Aguirre, a nuevas políticas productivas y renovadas relaciones jerárquicas sociales.

Hacia 1560 el capitán Francisco de Villagra asumiría el cargo de gobernador de Chile, lo cual iba a generar un retroceso en las medidas tomadas en 1558 , brindándoles a los encomenderos mayor disponibilidad de fuerza de producción para la minería (M. I. González Io). Se sabe que la regulación de la mano de obra indígena tuvo altibajos, lo que fue motivo de tensiones entre encomenderos, iglesia y gobierno (M. I. González IO-II), aunque para Copiapó no tenemos certeza de si se mantuvo el sistema implementado por Santillán. En 1580 se dictó una nueva tasa (tasa de Gamboa) con el propósito de brindar mayor protección a los indios encomendados. Si bien esta no fue instaurada en el corregimiento de La Serena (вNм, $M s$ ), se desconoce el porqué. ¿¿Se debió ello a que la de Santillán aún continuaba en aplicación, o, por el contrario, a que los encomenderos controlaban el Norte Chico? Solo nuevos estudios permitirán responder a dicho interrogante. No obstante, sabemos que a finales del siglo xvi la población encomendada de Copiapó estaba siendo diezmada, pudiendo más los encomenderos y su codicia, sus afanes de llegar a ser grandes señores en estos nuevos territorios, y crear así, como lo afirma Romano, feudos americanos a la imagen de Europa. 
Coincidimos en este análisis y esperamos que poco a poco salgan a luz documentos inéditos que permitan comprender mejor este periodo histórico desde dentro de la sociedad indígena. A su memoria dedicamos este estudio.

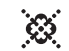

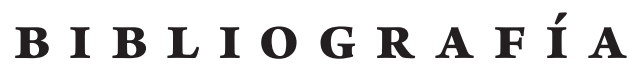

\section{F U E N T ES PR I M A R I S}

\section{A. Archivo}

Archivo General de Indias, Sevilla, España (AGI)

Gobierno $(G)$

Chile, 50, n. ${ }^{\circ}$ 6. "Confirmacion de encomienda de Fernando de Aguirre, términos

de la Serena”. I58I.

Chile, 322, n. ${ }^{\circ}$ 108. "Cedula de confirmacion de la encomienda en los terminos de la Serena, valle de Copiapó, Morro Moreno y Marquessa de don Fernando de Aguirre”. 1666.

Archivo Nacional de Chile, Santiago de Chile, Chile (ANch)

Capitanía General $(C G)$

Vol. I55, n. ${ }^{\circ}$ 3. "Autos seguidos por Bernabe de Riveros contra Joseph de Carvajal y

Juan Roco, por estancia de Camasquil”. 1633.

Vol. 48I, n. 46 . "Visita a las encomiendas del valle de Copiapo". 1708.

Vol. 578 , s. n. "Instrumentos del maestre de campo don Francisco de Cisternas". 1633. Real Audiencia $(R A)$

Vol. 50, s. n... "El protector de los Indios por el amparo y defenza de los del Valle de Copiapó contra el General Don Juan de Sisternas sobre el despojo de un Potrero en dicho valle y que de la Brea que hubiese sacado se les señale alguna parte”. I684.

Vol. 2467 , n. I 4. "Cacique de Copiapo José Taquia contra Juan de Morales Bravo, sobre reducción de los indios de Copiapó y Huasco”. 1685.

Biblioteca Nacional de Madrid, Madrid, España (BNM)

Manuscritos (Ms)

“Tasacion de los tributos de los yndios del Reino de Chille”. I580. 


\section{B. Impresos}

Actas del Cabildo de Santiago. Primer Libro de Actas del Cabildo de Santiago llamado jeneralmente Libro Becerro. De I54I-I557. I54I-I557. Santiago de Chile: Imprenta del Ferrocarril, I86I.

Bibar, Jerónimo de. Crónica y relación copiosa y verdadera de los reynos de Chile, doble versión facsímil y paleográfica editada por Irving A. Leonard. I558. Santiago de Chile: Fondo Histórico y Bibliográfico José Toribio Medina, 1966.

Frézier, Amédée. Voyage de la mer du Sud aux côtes du Chili et du Pérou. 1717. Dijon-Quetigny, 1995 .

Góngora y Marmolejo, Alonso de. Historia de Chile desde su descubrimiento hasta el año de I575. I575. Santiago de Chile: Imprenta del Ferrocarril, i862.

López de Velasco, Juan. Geografía y descripción universal de las Indias. 1574. Madrid: Edición Atlas, I97I.

Lovera, Pedro Mariño de. Crónica del Reino de Chile, escrita por el capitan don Pedro Mariño de Lovera. Dirijida al exmo. Señor don Garcia Hurtado de Mendoza, marques de Cañete, vice-rei y capitan jeneral de los Reinos del Perú y Chile. Reducida a nuevo método, y estilo por el padre Bartolomé de Escobar, de la Compañia de Jesus. 1595. Santiago de Chile: Imprenta del Ferrocarril, I865.

Santillán, Hernando de. "Relación de lo que el licenciado Fernando de Santillán, oidor de la Audiencia de Lima, proveyó para el buen gobierno, pacificación y defensa del reino de Chile”. I559. Colección de documentos inéditos para la historia de Chile - tomo XXVIII, editado por José Toribio Medina. Santiago de Chile: Imprenta Elzeviriana, I901, pp. 284-302.

---. "Relación de lo que el licenciado Fernando de Santillán, oidor de la Audiencia de Lima, proveyó para el buen gobierno, pacificación y defensa de Chile. I 4 de junio de I559". 1559. El salario de los indios y los sesmos del oro en la Tasa de Santillán, editado por Álvaro Jara. Santiago de Chile: Universidad de Chile, I961, pp. 95-108.

---. "Relación de lo que el licenciado Fernando de Santillán, oidor de la Audiencia de Lima, proveyó para el buen gobierno, pacificación y defensa de Chile. I 4 de junio de 1559 ". 1559. Fuentes para la historia del trabajo en el reino de Chile, legislación t. I, editado por Álvaro Jara. Santiago de Chile: Centro de Investigaciones de Historia Americana, 1965 , pp. I 4-27.

---. "Relación de lo que el licenciado Fernando de Santillán, oidor de la Audiencia de Lima, proveyó para el buen gobierno, pacificación y defensa de Chile”. 1559. Fuentes para la historia del trabajo en el reino de Chile. Legislación, I546-I8Io, t. I, editado por Álvaro Jara y Sonia Montesinos. Santiago de Chile: Editorial Andrés Bello, 1982, pp. 19-34. 
---. "Relación de lo que el licenciado Fernando de Santillán, oidor de la Audiencia de Lima, proveyó para el buen gobierno, pacificación y defensa de Chile, 4 de junio de 1559 ”. 1559. Trabajo y salario indigena, siglo XVI, editado por Álvaro Jara. Santiago de Chile: Editorial Universitaria, 1987, pp. 191-208.

---. "Relacion de las Visitas y tasas que el señor licenciado Fernando de Santillán oydor de su Magestad hizo de la cibdad de Santiago provincias de Chile de los repartimientos de yndios de sus terminos y de la cibdad de la Serena”. 1559. Pueblos originarios del Norte Florido de Chile, doble versión facsímil y paleográfica editada por Hernán Cortés Olivares, Patricio Cerda Carrillo y Guillermo Cortés Lutz. La Serena: Fondart, 2004, pp. 18-213.

Torres, Alonso de. "Declaración de Alonso de Torres. Cuarta información sacada de una probanza hecha por Lorenzo Maldonado, procurador de la ciudad de Santiago del Estero, contra el capitán Juan Núñez de Prado”. I554. Colección de documentos inéditos para la historia de Chile. t. x. Santiago de Chile: Imprenta Elzeviriana, I896, pp. 192-194.

Valdivia, Pedro de. "Al emperador Carlos V. La Serena, 4 de septiembre de 1545 ”. I5 45. Cartas de Relación de la Conquista de Chile. Santiago de Chile: Editorial Universitaria, I978, pp. 26-5I.

---. "Merced de encomienda a Francisco de Aguirre". 1549. Colección de documentos inéditos para la historia de Chile, t. xv. Santiago de Chile: Imprenta Elzeviriana, I898, pp. 220-222.

\section{I F U E N T ESSECUNDARIA S}

Bakewell, Peter. "La maduración del gobierno del Perú en la década de 1560 ”. Historia Mexicana, vol. 39, n. ${ }^{\circ}$ I, 1989, pp. 41-70.

Bittmann, Bente. "Interrelaciones étnicas establecidas a lo largo de la costa del norte de Chile y sur de Perú en el contexto de la colonia: Los camanchacas”. Estudios Atacameños, n. 7 , 1984, pp. 327-334. DOI: https://doi.org/I0.22199/s07181043.1984.0007.00031.

Castillo Gómez, Gastón. “Diaguitas arqueológicos y diaguitas etnohistóricos, una aproximación a la problemática étnica del valle de Elqui". Culturas surandinas. Huarpes y diaguitas. Actas Congreso Binacional Raices de Etnicidad; Región de Coquimbo, Chile - Provincia de San Juan, Argentina, editado por Arturo Volantines. La Serena: SA LC, 2OII, pp. 3I-IO2.

---. "Los períodos intermedio tardío y tardío: desde la cultura Copiapó al dominio Inca”. Culturas prehistóricas de Copiapó, editado por Hans Niemeyer, Miguel Cervellino y Gastón Castillo. Santiago de Chile: Museo Regional de Atacama, 1998, pp. 163-282. 
Contreras Cruces, Hugo. "Encomienda y servicio personal entre las comunidades indígenas de Chile central, I54I-I580". Tesis doctoral en Historia. Universidad de Chile, 2009.

Cornejo, Luis. "Sobre la cronología del inicio de la imposición cuzqueña en Chile". Estudios Atacameños, n. 47, 2014, pp. IOI-116. DoI: https://doi.org/10.4067/s0718I0432014000100007.

Cortés Larravide, Enrique. “¿Existió un grupo llamado Copiapó en el valle homónimo? Reflexiones a partir de los testimonios coloniales”. Revista Tiempo Histórico, n. ${ }^{\circ}$ I2, 2016, pp. 17-32. DOI: https://doi.org/10.25074/th.voir2.1383.

---. "La langue des Indiens de Copiapo au XVI ${ }^{\mathrm{e}}$ siècle: discussion et premières hypothèses". Enjeux méthodologiques en science du langage. Orientations, matériaux, contraintes, editado por Virginia Garin, Guillaume Roux y Maude Vaudot. París: L’Harmattan Collection Langue \& Parole, 201 4, pp. 49-70.

---. "La pérdida de las tierras de los indios de Copiapó (siglos XVI-XIX): economía extractivista colonial hispana en el norte semiárido chileno". Diálogo Andino, n. ${ }^{\circ}$ 64, 202 I, pp. I87-198.

Cortés Olivares, Hernán. "Evolución de la propiedad agraria en el Norte Chico (siglos XVI-XIX)". Dinámicas de los sistemas agrarios en Chile árido: la región de Coquimbo, editado por Patrick Livenais y Ximena Aranda. Santiago de Chile: Universidad de Chile, IRD, Universidad de La Serena, LOM Ediciones, 2003, pp. 33-64. DoI: https:// doi.org/10.4000/books.irdeditions.24905.

---. Introducción. Pueblos originarios del Norte Florido de Chile, editado por Hernán Cortés Olivares, Patricio Cerda Carrillo y Guillermo Cortés Lutz. La Serena: Fondart, 2004, pp. 13-17.

--.. "El origen, producción y comercio del pisco chileno I546-1931". Universum, vol. 20, n. 2 , 2005, pp. 42-8I. DOI: https://doi.org/10.4067/s0718-23762005000200005.

Garrido Escobar, Francisco. "El camélido sagrado y el hombre de los valles: Una aproximación a la Cultura Copiapó y sus relaciones a partir de la alfarería”. Tesis de pregrado. Universidad de Chile, 2007.

Góngora, Mario. Encomenderos y estancieros. Estudios acerca de la Constitución social aristocrática de Chile después de la Conquista, I580-1660. Santiago de Chile: Universidad de Chile, 1970.

González Godoy, Carlos. "Síntesis de la prehistoria alfarera tardía del valle de Copiapó: desde las sociedades agrícolas locales (cultura Copiapó) a la presencia del Tawantinsuyu (1000 d. C. aprox.-1536 d. C.)”. Bajo la Lupa, 2018, s. p.

González Pomes, María Isabel. "La encomienda indígena en Chile durante el siglo XviII". Historia, vol. 5, 1966, pp. 7-103. 
Hidalgo Lehuedé, Jorge. "Algunos datos sobre la organización dual en las sociedades protohistóricas del Norte Chico de Chile. El testimonio de los cronistas”. 1971. Historia andina en Chile, de Jorge Hidalgo Lehuedé. Santiago de Chile: Editorial Universitaria, 2004, pp. 25-32.

Itier, César. "La langue de Copiapo”. Manuscrito. 20 Io.

Jara, Álvaro. El salario de los indios y los sesmos del oro en la Tasa de Santillán. Santiago de Chile: Universidad de Chile, 196r.

Murra, John V. “El 'control vertical' de un máximo de pisos ecológicos en la economía de las sociedades andinas". Visita a la Provincia de León de Huanuco en 1562, Iñigo Ortiz de Zúñiga, editado por John V. Murra. Huanuco: Universidad Emilio Valdizán, 1972, pp. 429-472.

Pärssinen, Martti. Tawantinsuyu. ElEstado inca y su organización politica. Lima: IFEA, 2003.

Romano, Ruggiero. Lesmécanismes de la conquête coloniale : les conquistadores. París: Flammarion, 1972.

Ruiz Rivera, Julián B. Encomienda y mita en Nueva Granada. Sevilla: CSIC, I975.

Yaeger, Timothy J. "Encomienda or Slavery? The Spanish Crown's Choice of Labor Organization in Sixteenth-Century Spanish America”. The Journal of Economic History, vol. 55, n. 4, 1995, pp. 842-859. DOI: https://doi.org/10.1017/s0022050700042182.

Zavala, Silvio. La encomienda indiana. Madrid: Centro de Estudios Históricos, 1935.

Zúñiga Fuentes, Erika. "Esclavitud infantil. Otra historia de la 'conquista' de los pueblos originarios. Una lectura a partir del testimonio de Hernando de Santillán”. Temas de Educación, vol. 20, n. ${ }^{\circ}$, 2014 , pp. 107-I20. 